\title{
Estimation of Hand Bones Age in Sudanese Children
}

\author{
Safaa A. Y. Mohammed ${ }^{1 *}$, Anas O. A. Hamdoun ${ }^{1}$, Abd Elmoniem S. Elmardi ${ }^{2}$
}

\author{
${ }^{1}$ Department of Human Anatomy, Faculty of Medicine, University of Gezira Sudan \\ ${ }^{2}$ Faculty of Medicine, Khartoum University Sudan
}

\begin{tabular}{l|l|l|}
\hline $\begin{array}{l}\text { DOI: } 10.36347 / \text { sasjm.2021.v07i03.010 } \\
\text { *Corresponding author: Safaa Mohammed }\end{array}$ & Received: 06.03.2021 | Accepted: 24.03.2021 | Published: 30.03 .2021 \\
\hline Abstract & Original Research Article \\
\hline
\end{tabular}

Bone age estimation is one of the important applications of hand age radiography in the area of pediatrics, especially for the diagnosis, endocrinological problems and growth disorders. To investigate whether the commonly used international methods for assessment of bone age can be applicable for Sudanese children, and to evaluate the Sudanese data base of skeletal age putting into consideration the ethnic variability and socioeconomic status, which affect bone growth. The study consisted of 305 Sudanese patients 167 males' a n d 138 females with different chronological ages. These radiographs were compared with radiographic atlas of the skeletal development of the hand and wrist Greulich- Pyle atlas and Pocket atlas of skeletal age. The radiograph was interpreted by and expert pediatric radiologist who is unaware of the chronological age of the children. No statistically significant difference is found between the chronological age and age measured by radiologist using Pocket atlas and Radiographic atlas GreulichPyle atlas. The results suggest that Sudanese children may have the same pattern of skeletal maturation from that of American children from which the Greulich-Pyle standards is derived. And the study recommend more than one reader is interpreter in the future for the bone age to evaluate interobserver variability and hence to improve accuracy and to avoid bias.

Keywords: Hand Bones Age, Skeletal Age, Chronological Age, Children.

Copyright (C) 2021 The Author(s): This is an open-access article distributed under the terms of the Creative Commons Attribution 4.0 International License (CC BY-NC 4.0) which permits unrestricted use, distribution, and reproduction in any medium for non-commercial use provided the original author and source are credited.

\section{INTRODUCTION}

Bone age is an indicator of the skeletal and biological maturity of an individual. This is different from chronological age, which is calculated using the date of birth of an individual. Bone age is often requested by pediatricians and endocrinologists for comparison with chronological age for diagnosing diseases which result in tall or short stature in children. Serial measurements are also used to assess the effectiveness of treatments for these diseases [1]. Age may be defined in several ways: bone age, morphological age, age at development of secondary sexual characteristics, age at menarche and dental age. These parameters have all been described as means to define physiological age [2]. 18 The time when a patient will reach puberty and even when the pubertal growth spurt (PGS) will occur may be estimated. However, these different types of age have a low correlation, and there are individual variations according to sex, ethnicity, geographic location, genetic factors, climate, nutrition and socioeconomic status. Because of that, the determination of specific chronological ages as the beginning of puberty in male and female patients is no longer used [2-4].
Generally, bone age assessment is diagnosed through a radiography X-ray image of the left-hand region, which is the non-dominant hand. X-ray is a powerful imaging modality where it is even used in astronomy-related observations [5]. The age differences can be observed through an X-ray image, especially regions with the bone growth plates, where they will become thinner as a child grows older and totally disappears once he becomes an adult.

In early 1960, the most popular assessment is done through the Greulich and Pyle (G\&P) method [6], which subjectively compares the captured hand X-ray with a set of hand atlas images. In general, the reliability of this method is low due to the high bias in inter and intra-observers, where clinical experience plays a crucial factor in reporting the right assessment. Rather than looking at the whole X-ray image, the method by Tanner-Whitehouse (TW) [7] is looking at the specific regions on the X-ray image in order to reduce the assessment subjectivity [8]. Therefore, the accuracy of bone age assessment is very important. Although manual bone age assessment methods have been used for a long time, the main problem with these methods is inter- and intra-observer variability. 
Recently, several computerized systems for bone age assessment have been developed.

In fact, a radiograph of the hand and wrist can at best reflect the maturity of the bones that are depicted on that film, and the recognition of the shapes and changes of configuration of bones provides only a limited insight into maturational processes [9]. Nevertheless, bone age (BA) is considered an important indicator of maturity and is the only size-independent indicator of biological maturity routinely used from birth to adulthood. Many parameters correlate better with BA than with chronological age (CA) (e.g., height velocity, menarche, muscle mass and bone mineral mass [10].

Several studies have been published on the intra and interobserver variance of BA [11-14]. King et al. [11] provide an overview of many of these studies but it is difficult to draw any conclusions from their table because of conflicting results due to differing study designs, differing experience of the raters and differing measures of the interrater variability. A recent study found a standard error of 0.55 years among the readings of a group of 5 pediatric endocrinologists and a standard error of 0.61 years among 7 radiologists. So, the aim of this study to estimate of hand bones age in Sudanese children.

\section{METHODOLOGY}

A questionnaire was filled for all subjects which investigating different factors including the age, sex of the participant, date and place of birth, place of resident, tribe, socioeconomic status and the past medical history in addition to a small clinical examination.

Study area: From central Sudan, the majority of the subjects were examined and interviewed at Wad
Madani Police hospital and Wad Madani Military hospital. The remainders were examined at Gafar Ibn Auf Children's hospital and Khartoum educational hospital.

Study population: The study recruited 305 Sudanese patients 167 males and 138 females, with various ages from one month to 18 years old. The children were from all social classes, with variable socioeconomic status and were free from nutritional problems at the time of radiography.

Inclusion criteria: Age from One months to 18 years, old males and females, to be resident in central Sudan, Patients with history of acute condition, not affecting and Bone growth or bone age e.g., trauma in radius.

Exclusion criteria: Age less than One months and age more than 18 years, Children with chronic illness that affected bone age e.g., diabetes, sickle cell anemia, rickets, etc. Children with trauma to the carpal bones, Children, who had congenital, endocrinological or other serious disease and X-rays of children with poor position, inadequate quality or inadequate information of chronological age and sex.

\section{RESULTS}

Estimation of hand bones age in Sudanese children was the study content from 305 Sudanese patients 167 males and 138 females. Some carpal bones may overlap over each other as growth proceeds and thus it is more difficult to make an assessment of skeletal age for patients older than 9-12 years of age, therefore, in our assessment of the left-hand radiograph's combination of the carpal, metacarpal, phalanxes and distal end of the radius and ulna are used to assess bone age rather than carpal bones alone.

Table-1: Show descriptive study of the Chronological age and Bone age

\begin{tabular}{|l|l|l|l|}
\hline Variables & Mean & Std. Dev & Std. Error Mean \\
\hline Chronological age of & 114.02 & 58.485 & 3.648 \\
volunteers in month & & & \\
$\begin{array}{l}\text { Pocket atlas of skeletal age } \\
\text { Radiographic atlas of the skeletal }\end{array}$ & 112.366 & 59.4194 & 3.7065 \\
\hline
\end{tabular}

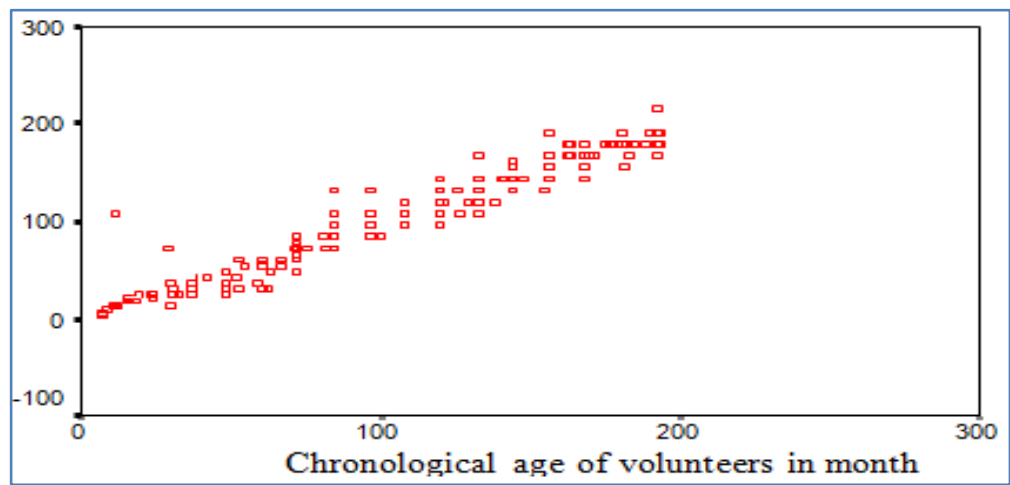

Fig-1: Show Scatter diagram of age estimated by the chronological age and pocket atlas 


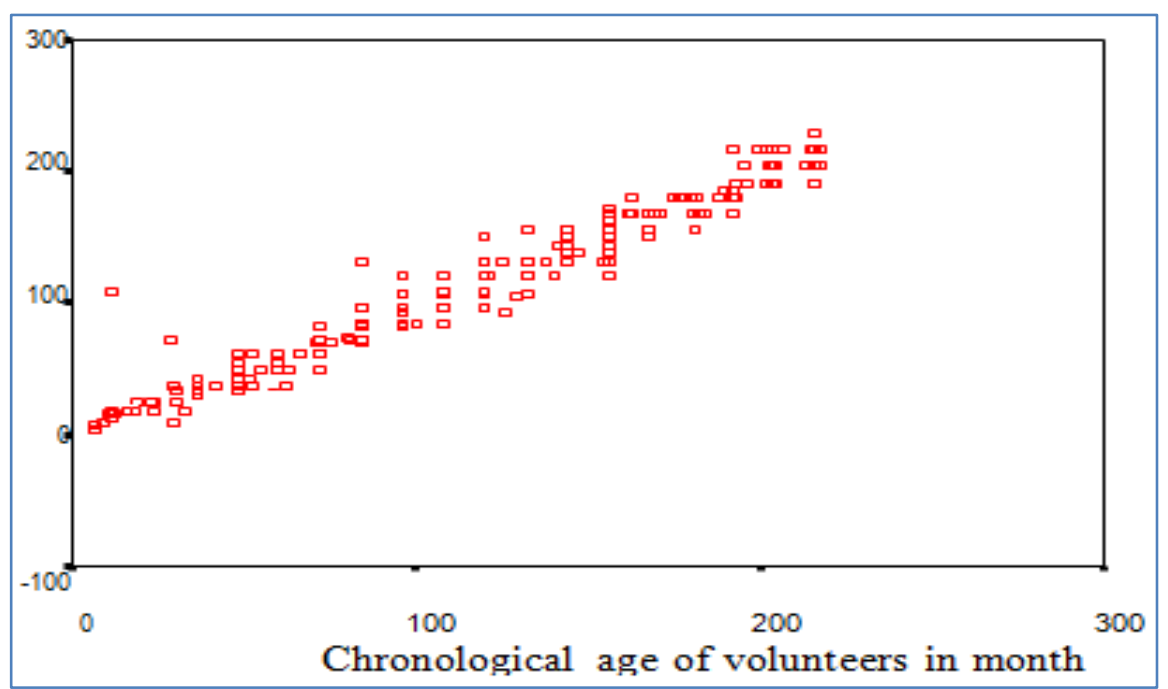

Fig-2: Show Scatter diagram of age estimated by the chronological age and Greulich and Pyle atlas



Fig-3: Show spaces between the carpal bones according to the chronological age

Table-2: Show correlation between the Chronological age and Bone age

\begin{tabular}{|l|l|l|l|}
\hline $\begin{array}{l}\text { Chronological and bone } \\
\text { age }\end{array}$ & $\begin{array}{l}\text { Chronological age of } \\
\text { volunteer in month }\end{array}$ & $\begin{array}{l}\text { Pocket atlas of } \\
\text { skeletal age }\end{array}$ & $\begin{array}{l}\text { Radiographic atlas of the } \\
\text { skeletal development of the } \\
\text { hand and wrist }\end{array}$ \\
\hline $\begin{array}{l}\text { Chronological age of } \\
\text { volunteers in month }\end{array}$ & 1 & $.975(* *)$ & $.977(* *)$ \\
& 257 & .000 & .000 \\
& .000 & 257 & 257 \\
& 257 & .000 & .000 \\
$\begin{array}{l}\text { Pocket atlas of skeletal } \\
\text { age }\end{array}$ & $.975(* *)$ & 1 & 257 \\
& .000 &. & $.992(* *)$ \\
& 257 & 257 & .000 \\
$\begin{array}{l}\text { Radiographic atlas of the } \\
\text { skeletal development of } \\
\text { the hand and wrist }\end{array}$ & $.977(* *)$ & $.992(* *)$ & 257 \\
& .000 & .000 & 1 \\
\hline
\end{tabular}

Correlation is significant at the 0.01 level (2-tailed). 


\section{DISCUSSION}

Estimation of hand bones age in Sudanese children was the study recruited 305 Sudanese patients 167 males and 138 females, Table 1 . Gives the means and standard deviations for chronological age and the bone age evaluated by an expert pediatric radiologist. Mean chronological age is 114 month and pocket atlas are 112 month and mean bone age in radiographic atlas is 111 months. And found that no statistically significant difference between the chronological age and bone age measured by radiologist using Pocket atlas and Radiographic atlas (Greulich-Pyle atlas) figures (1 and 2). $\mathrm{P}$ value was 0.00 , as comparing the chronological age with bone age by chi-square cross tabulation test.

The study shows that the spaces between all the carpal bones have been reduced with advance of the age, figure 3 . In the ninth year, the trapezium and trapezoid will overlap. In the eleventh year, the distal tip of the hook of the hamate is just becoming discernible.

Table 2. Gives correlation between chronological age and bone age assessed with the Greulich and Pyle atlas and Pocket atlas in children of all ages. Correlation is significant at the 0.01 level.

The findings of this study show that there was no significant difference between chronological age and bone age and this is different from the findings of Groell et al. [15] which showed that there were significant differences between chronological age and bone age and they concluded that the Greulich and Pyle (G\&P) Atlas must be used with reservation. It however confirms the findings of Ontel et al. [16] who stated that standards of G\&P skeletal age are applicable in white boys. My findings indicated that Sudanese children have the same pattern of skeletal maturation not vary from Greulich and Pyle atlas which is drive from American children. Based on these findings, we concluded that the standards of G\&P skeletal age can be applied in Sudanese children with accuracy and reliability and without reservation. This, however, is not compatible with the conclusions of Chiang $\mathrm{KH}$ et al. [17] which proposed that some modification of the G\&P Atlas was necessary to enhance ability with accuracy, reliability and consistency in determination of children's bone age in Taiwan. It appears thus, that the G\&P Atlas is not valid for all countries. For this reason, each country must have its own atlas for the determination of bone age. Also, found some carpal bones appear before their expected normal appearance and others are retarded from the normal growth this because the development is highly variable in different populations and may be affected by many factors such as socioeconomic, genetic and environmental factors.
Racial, socioeconomic and environmental differences between populations may cause differences in skeletal maturation. This confirms that in our study there are some differences of skeletal maturation among different populations. Also, found that there was strong correlation between the chronological age and measured age. Mean chronological age differs from mean bone age by two to three months. In the wrist, the growth of carpal bones usually relies on its sizes and characteristic shape. Accordingly, the method of skeletal age assessment based on carpal bone features is to find the numbers of carpal bones and their sizes as features.

\section{CONCLUSION}

Estimation of hand bones age in Sudanese children was the study recruited 305 Sudanese patients 167 males and 138 females. The results suggest that Sudanese children may have a same tempo of skeletal maturation during development resembling the American children from which GP standards were derived. There is a discrepancy of more than 4 month between the chronological age and the measured bone age in some ages. I believe that some modification of the GP Atlas is necessary to enhance our ability to determine skeletal maturation with accuracy, reliability and consistency. Therefore, GP Atlas may be applicable to Sudanese children. This can be achieved by doing a larger survey for bone age considering the ethnic and socioeconomic variations.

\section{REFERENCES}

1. Martin DD, Wit JM, Hochberg Z, Sävendahl L, van Rijn RR, Fricke O. The Use of Bone Age in Clinical Practice - Part 1. Hormone Res Paediatr. 2011;76:1-9.

2. Prates NS. Crescimento crânio-facial e maturação óssea: estudo em crianças nascidas em Piracicaba, portadoras de oclusão dentária normal [tese]. Campinas: Universidade Estadual de Campinas; 1976.

3. Bowden BD. Epiphysal changes in the hand/wrist area as indicators of adolescent stage. Austr Orthod J Pediat. 1976;4(3):87-104

4. Magnunsson TE. Skeletal maturation of the hand in Iceland. Acta Odontol Scand. 1979;37(1):21-8.

5. Nazria, N.; Annuar, A. X-ray sources population in ngc 1559. J. Kejuruter. 2020, 3, 7-14.

6. Greulich, WW, Pyle SI. Radiographic atlas of skeletal development of the hand and wrist. Am. J. Med Sci. 1959, 238, 393.

7. Carty, H. Assessment of skeletal maturity and prediction of adult height. J. Bone Jt. Surg. 2002, 84-B, 310-311.

8. Fernandez JR, Zhang A, Vachon L, Tsao S. Bone age assessment in Hispanic children: digital hand atlas compared with the Greulich and Pyle (G\&P) atlas. InMedical Imaging 2008: PACS and Imaging Informatics 2008 Mar 11 (Vol. 6919, p. 691918). International Society for Optics and Photonics. 
9. Hochberg Z: Endocrine Control of Skeletal Maturation. Basel, Karger; 2002.

10. Bass S, Pearce G, Bradney M, Hendrich E, Delmas PD, Harding A, Seeman E: Exercise before puberty may confer residual benefits in bone density in adulthood: studies in active prepubertal and retired female gym nasts. J Bone Miner Res. 1998; 13: 500-507.

11. King D, Steventon D, O’Sullivan M, Cook A, Hornsby V, Jefferson I, King P. Reproducibility of bone ages when performed by radiology registrars: an audit of Tanner and Whitehouse II versus Greulich and Pyle methods. Br J Radiol.1994; 67: 848-851.

12. Van Rijn RR, Lequin MH, Robben SGF, Hop WCJ, van Kuijk C: Is the Greulich and Pyle atlas still valid for Dutch Caucasian children today? Pediatr Radiol. 2001; 31: 748-752.

13. Lynnerup N, Belard E, Buch-Olsen K, Sejrsen B, Damgaard-Pedersen K: Intra- and in terobserver error of the Greulich-Pyle method as used on a
Danish forensic sample. Forensic Sci Int. 2008; 179: $1-6$.

14. Johnson GF, Dorst JP, Kuhn JP, Roche AF, Davila GH: Reliability of skeletal age assess ments. Am J Roentgenol Radium Ther Nucl Med. 1973; 118: 320-327.

15. Groell R, Lindbichler F, Riepl T, Gherra L, Roposch A, Fotter R. The reliability of bone age determination in central European children using the Greulich and Pyle method. The British journal of radiology. 1999 May;72(857):461-4.

16. Ontel I, Vladut A. Impact of drought on the productivity of agricultural crops within the Oltenia Plain, Romania. Geographica Pannonica. 2015;19(1):9-19.

17. Kh. ABDULLAEV FA, Gammal A, Kamchatnov AM, Tomio L. Dynamics of bright matter wave solitons in a Bose-Einstein condensate. International Journal of Modern Physics B. 2005 Sep 10;19(22):3415-73. 